\title{
To Study the Extent of Awareness and Utilization of the Selected Central Government Schemes by the Women
}

\author{
B. Prashanthi ${ }^{1 *}$, R. Geetha Reddy ${ }^{2}$ and B. Spandana ${ }^{2}$ \\ ${ }^{1}$ Department of Human Development and Family Studies, Telangana, India \\ ${ }^{2}$ Department of Extension Education and Communication Management, Telangana, India \\ *Corresponding author
}

\section{A B S T R A C T}

Keywords

Central government schemes, Girl child, Adolescent women, ICDS, SSY, KGBV, SABLA

Article Info

Accepted:

17 June 2019

Available Online:

10 July 2019
The present study was undertaken with a view to study the extent of awareness and utilization of the selected central government schemes by the women in the Jogulama Gadwal district in Jogulama Gadwal (Rural) of Telangana state. The ongoing schemes viz. ICDS, SSY, KGBV, SABLA were selected to study the extent of awareness among women. A total of 60 women were selected and majority of the respondents belonged to the 2545 year's age groups. The data was collected through personal interviews with the help of the structured schedules and was analyzed using standard statistical tools. The results revealed that, majority of the respondents had awareness KGBVs $(80 \%)$ were as $(50 \%)$. As much as $23 \%$ girls benefitted from the SABLA Programme.

\section{Introduction}

The ministries of the Government of India have come up with various useful schemes from time to time. These schemes could be either central, state specific or joint collaboration between the Centre and the states.

\section{Integrated Child Development Services (ICDS) Scheme}

The Integrated Child Development Services (ICDS) was launched on $2^{\text {nd }}$ October 1975. Today, ICDS Scheme represents one of the world's largest and most unique programme for early childhood development.

Ministry of Women and Child Development is implementing various schemes for welfare, development and protection of children.

\section{Services}

Supplementary nutrition

Health check-up

Immunization

Nutrition \& health education

Referral services

Pre-school non-formal education 
Children in the age group 0-6 years constitute around 158 million of the population of India (2011 census). These Children are the future human resource of the country. Ministry of Women and Child Development is implementing various schemes for welfare, development and protection of children.

\section{Sukanya Samriddhi Yojana (SSY)}

Sukanya Samriddhi account is a famous and popular scheme backed by the Government of India. As part of 'Beti Bachao, Beti Padhao' campaign started by the Government, this is a saving scheme for the benefit of the girl child.

The scheme helps to save the future of a girl child, encourage parents to build a fund to meet the expenditure for education and marriage of their girl child.

\section{Benefits}

The Sukanya Samriddhi Yojana account pays an interest of $9.1 \%$ for each financial year. The interest rate offered in this is the highest when compared to other small saving schemes. This scheme is also one of the most tax-saving ones. One of the best features of this scheme is the provision of a lock-in period. You can certainly build an adequate amount to provide a bright future for your girl child. The account can be transferred too to another place if required.

\section{Eligibility}

The account can be opened by legal guardians or parents of a girl child only. The age of the girl child should not be more than 10 years. A certificate for proof of age has to be submitted along with the form. Only two accounts can be opened by parents or legal guardians of the child. An amount of Rs $250 /-$ is required to open the account. After completion of 21 years, the account can be closed.

\section{Kasturba Gandhi BalikaVidyalaya (KGBV)}

Kasturba Gandhi Balika Vidyalaya (KGBV) Scheme was launched by Government of India in August 2004, the education system more responsive to the needs of marginalised girls and to enhance their access and retention. Under the scheme, residential schools for girls at upper primary levels (VI to X) were set up in the Educationally Backward Block (EBB) s, towns and minority concentrated areas all over the country. The scheme provides upper primary level education for girls who are either drop out or never enrolled in the age group of 10-14 years belonging to Scheduled Castes (SC), Scheduled Tribes (ST), Other Backward Classes (OBC), Minority communities and children of families of Below Poverty Line (BPL).

\section{Objective}

The objective of KGBV is to ensure that quality education is feasible and accessible to the girls of disadvantaged groups of society by setting up residential schools with boarding facilities at elementary level.

\section{The Rajiv Gandhi Scheme for Empowerment of Adolescent Girls (RGSEAG) Sabla}

The Rajiv Gandhi Scheme for Empowerment of Adolescent Girls (RGSEAG) Sabla is a centrally sponsored program of Government of India initiated on April 1, 2011 under Ministry of women and child Development. The scheme focuses more on the needs of outof-school adolescents and promotes learning.

\section{Objectives}

Enable the Adolescent girls for selfdevelopment and empowerment.

Improve their nutrition and health status. 
Promote awareness about health, hygiene, nutrition, adolescent reproductive and sexual health (ARSH) and family and child care.

Upgrade home-based skills, life skills and integrate with the National Skill Development Program (NSDP) for vocational skills.

Mainstream out of school adolescent girls into formal/non formal education.

Provide information/guidance about existing public services such as $\mathrm{PHC}, \mathrm{CHC}$, Post Office, Bank, Police Station, etc.

The scheme focuses more on the needs of outof-school adolescents and promotes learning.

\section{Studies related to ICDS in India}

Mani and Indulekha (2013) studied the "Impact of ICDS with regard to the intellectual, social and physical development of preschoolers" revealed that the ICDS beneficiary children exceeded their non-ICDS peers in their intellectual, social and physical development.

The result also showed that the study variables-Intellectual, Social and Physical development-are significantly interrelated and influenced one another.

Arora et al., (2006) parents believe that anganwadi centre is the best place for their children to get good nutrition, health and education, free of cost. They consider Anganwadi as the best place for children as their children get better nutrition and education for their overall development.

Dhawan and Rahgir (2002) reported that 48 per cent ICDS beneficiaries belonged to middle caste, followed by lower caste (46.50\%) However, only 5.50 per cent ICDS beneficiaries were of high caste category.

\section{Studies related to SSY in India}

Rameshwar and Rasal expressed his view that this SSY scheme is a beneficial scheme to girl children for their literacy and this is one of the schemes that provides highest rate of interest.

Venkatachalam and Ravindran putforth their opinion that this SSY scheme is especially for Indian parents and guardians to design for girl's higher education or marriage needs so that her financial needs won't be a burden to the family.

\section{Studies related to KGBVs in India}

Government of India (2013) conducted the Second national evaluation of KGBV programme and the findings reveal that many states seem to believe that this programme is for any SC, ST, OBC, minority and BPL girls in the surrounding areas. Identification of BPL is problematic and the team found that in some KGBVs, girls who were not eligible were enrolled.

Rawat (2011) conducted a study on status and functioning of KGBVs Uttarakhand and found that the parents are generally happy with the education and vocational skill training being imparted to their children. They also reported having noticed attitudinal and behavioral changes in their daughters towards betterment on the whole, KGBVs have certainly make a significant contribution in mainstreaming the out-of-school and drop-out girls belonging to the socio-economically backward communities living in Educationally Backward Blocks (EBBs).

\section{Studies related to Sabla in India}

Pujar et al., (2014) concluded that intervention on life skill education was helpful for the rural adolescent girls to take positive actions and improving their coping skills of stress and 
problem solving ability. As health and nutrition is important for the adolescent girls but for overall development of girls, life skills and vocational skills are also required especially for rural girls. All adolescent girls need life skills for their better and holistic development. They need to be looked at in terms of their needs both as a group as well as individuals as they are the future productive members of the society. Recognizing the unmet needs of adolescent girls, Rajiv Gandhi Scheme for Empowerment of Adolescent Girls - Sabla has been launched as a comprehensive intervention for Adolescent girls in the age-group of 11-18 years, with a focus on out of school girls.

Arati (2016) to find out the influence of personal variables on core affective life skills of adolescents, it was shown that order of birth and family income has significant influence on interpersonal relationship dimension of life skills. Gender, number of siblings and family type has no significant influence on core affective life skills. Good support from the family can equip the children with skills for life.

\section{Materials and Methods}

The present study was conducted in rural area of Jogulama Gadwal district in Jogulama Gadwal (Rural) of Telangana state by using ex-post facto research design. A total of 60 women were selected by purposive sampling method. The data from the respondents was collected through personal interviews with the help of the structured schedules and analyzed using standard statistical tools.

\section{Results and Discussion}

The information given in table 1 indicates that most of the respondents $(33 \%)$ comes under the age Range of 25-35 Years followed by 3545 years $(26 \%)$ almost equal samples that is
(20\%) comes under the age group below 25 years and more than 45 years (Table 1).

It was observed from the table 2. Most of the respondents that is $(36 \%)$ comes under $\mathrm{BC}$ category followed by SC (26\%), OC (20\%) and ST (16\%).

The information given the table indicates most of the $33 \%$ of the respondents are illiterates followed by below $10^{\text {th }}$ class $23 \%$ an equal sample belongs to $10^{\text {th }}$ class and degree were as few $10 \%$ of the sample had studied intermediate (Table 3).

The information given the table indicates Majority of the 33 respondent of the sample monthly income 15,000-25000 followed by $30 \%$ where having income above 25,000 all most equal sample that $20 \%$ and $16 \%$ where having income between 10,000-15000 and less than 10,000 respectively (Table 4).

From the above figure 1, it can be observed that majority of the respondents $90 \%$ knows about the ICDS scheme were as more than half the respondents $60 \%$ didn't had information regarding SSY majority of the respondents that is $80 \%$ known about the KGBVs were as $77 \%$ did not had any information about the SABLA.

From figure 2, it can be observed majority of the respondents KGBVs girls $(80 \%)$ were as $(50 \%)$ girls in ICDS followed by $(33 \%)$ of lactating mothers and $16 \%$ of pregnant women. Benefitted were as $23 \%$ girls benefitted the SABLA Programme.

It can be observed that most of the respondents $30 \%$ came to knew about these scheme through Grama panchayat meetings followed by advertisements on TV 23\%, SHG group $20 \%$ and newspapers $13 \%$ were as few of the respondents $7 \%$ knew through the family members and equal percentage that is 
$3 \%$ of the samples knew relatives and respondents were not benefitted other reasons. neibhourhood (Figure 3).

From figure 4, it can be observed majority of It can be observed more than half the respondents Perceptions these programmes good for them were as $26 \%$ of the respondents the respondents $(66 \%)$ were not benefitted had bad perception about these programmes because of lack of awareness and no voter list and $(36 \%)$ of the respondents were not Figure 5 . benefitted migration. And $30 \%$ of the

Table.1 Distribution of the respondents according to age

\begin{tabular}{|l|l|l|l|}
\hline S.NO & Age (in years) & F & \% \\
\hline 1. & Below 25 years & 12 & 20 \\
\hline 2. & 25-35 years & 20 & 33 \\
\hline 3. & 35-45 years & 16 & 26 \\
\hline 4. & More than 45 years & 12 & 20 \\
\hline
\end{tabular}

Table.2 Caste wise distribution of the respondents

\begin{tabular}{|l|l|l|l|}
\hline S.NO & Caste & F & \% \\
\hline 1. & OC & 12 & 20 \\
\hline 2. & BC & 22 & 36 \\
\hline 3. & SC & 16 & 26 \\
\hline $\mathbf{4 .}$ & ST & 10 & 16 \\
\hline
\end{tabular}

Table.3 Distribution of respondents on the basis of educational levels

\begin{tabular}{|l|l|l|l|}
\hline S.NO & Educational status & F & \% \\
\hline $\mathbf{1 .}$ & Degree & 10 & 16 \\
\hline $\mathbf{2 .}$ & Inter & 6 & 10 \\
\hline $\mathbf{3 .}$ & $10^{\text {th Class }}$ & 10 & 16 \\
\hline $\mathbf{4 .}$ & Below $10^{\text {th Class }}$ & 14 & 23 \\
\hline $\mathbf{5 .}$ & Illiterate & 20 & 33 \\
\hline
\end{tabular}

Table.4 Distribution of respondents on basis of monthly income

\begin{tabular}{|l|l|l|l|}
\hline S.NO & Monthly income & F & \% \\
\hline 1. & More than 25,000 & 18 & 30 \\
\hline 2. & $15,000-25,000$ & 20 & 33 \\
\hline 3. & $10,000-15,000$ & 12 & 20 \\
\hline 4. & Less than 10,000 & 10 & 16 \\
\hline
\end{tabular}


Fig.1 Awareness of the schemes

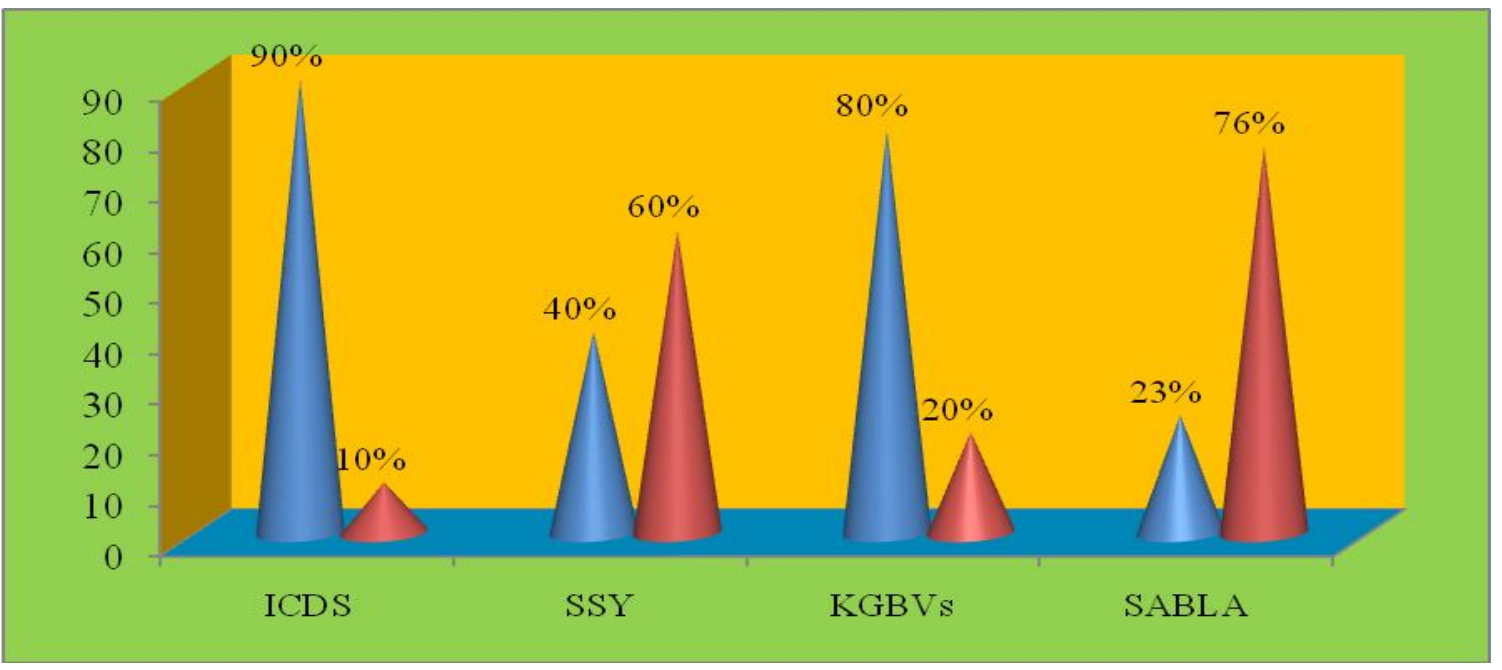

Fig.2 Beneficiaries of the scheme

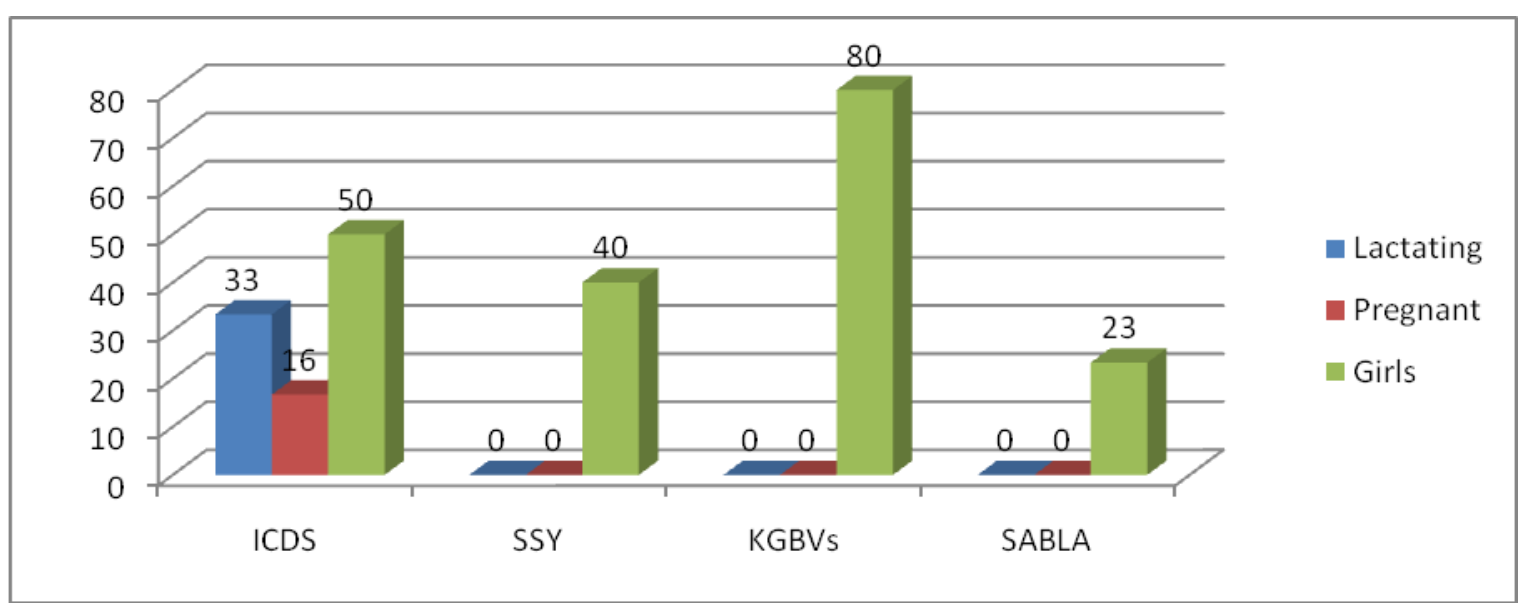

Fig.3 Sources of information about these schemes

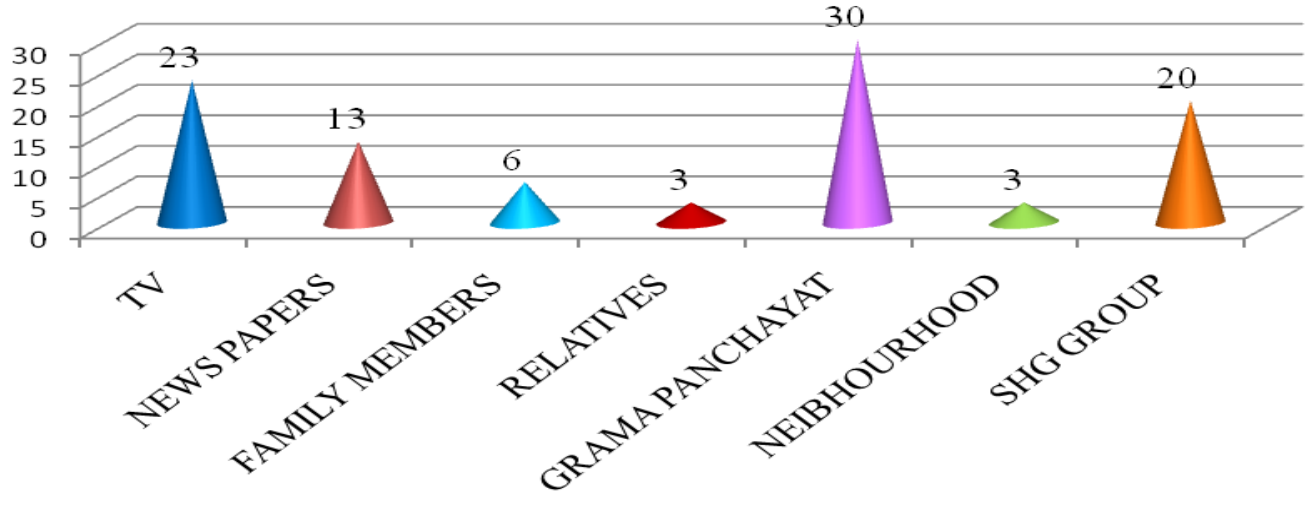


Fig.4 Reasons for not benefitted the schemes

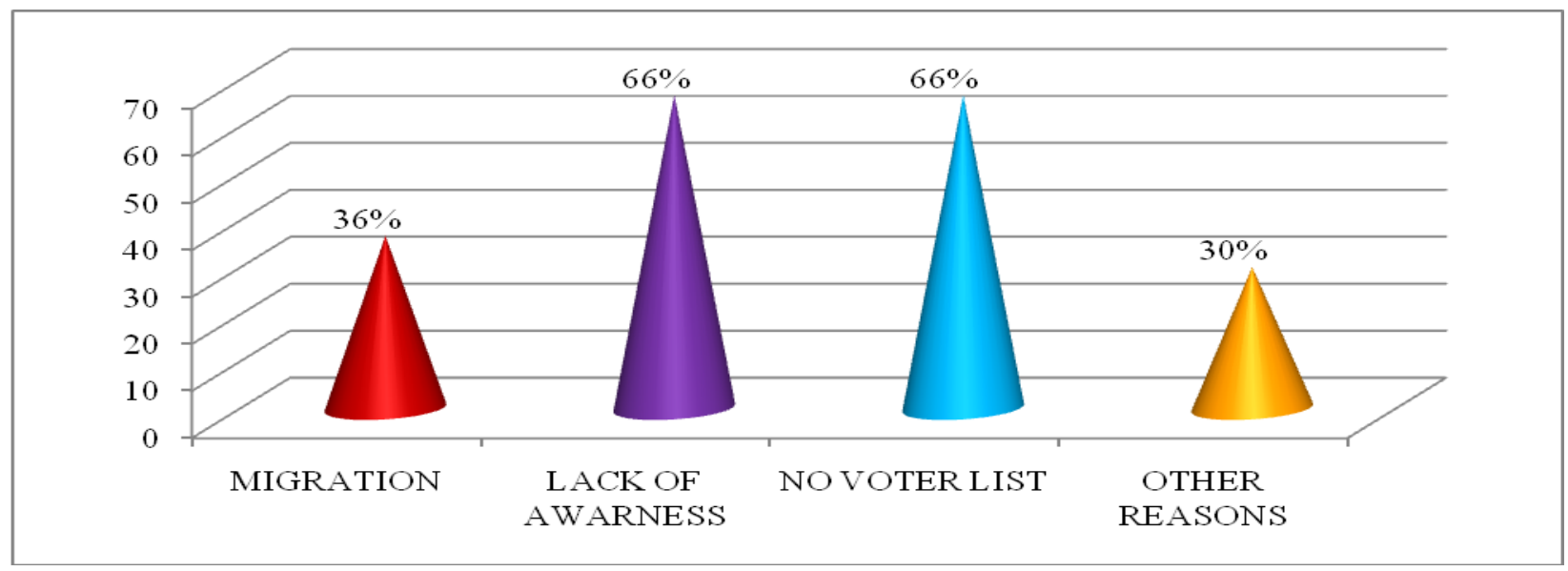

Fig.5 Opinion on the schemes

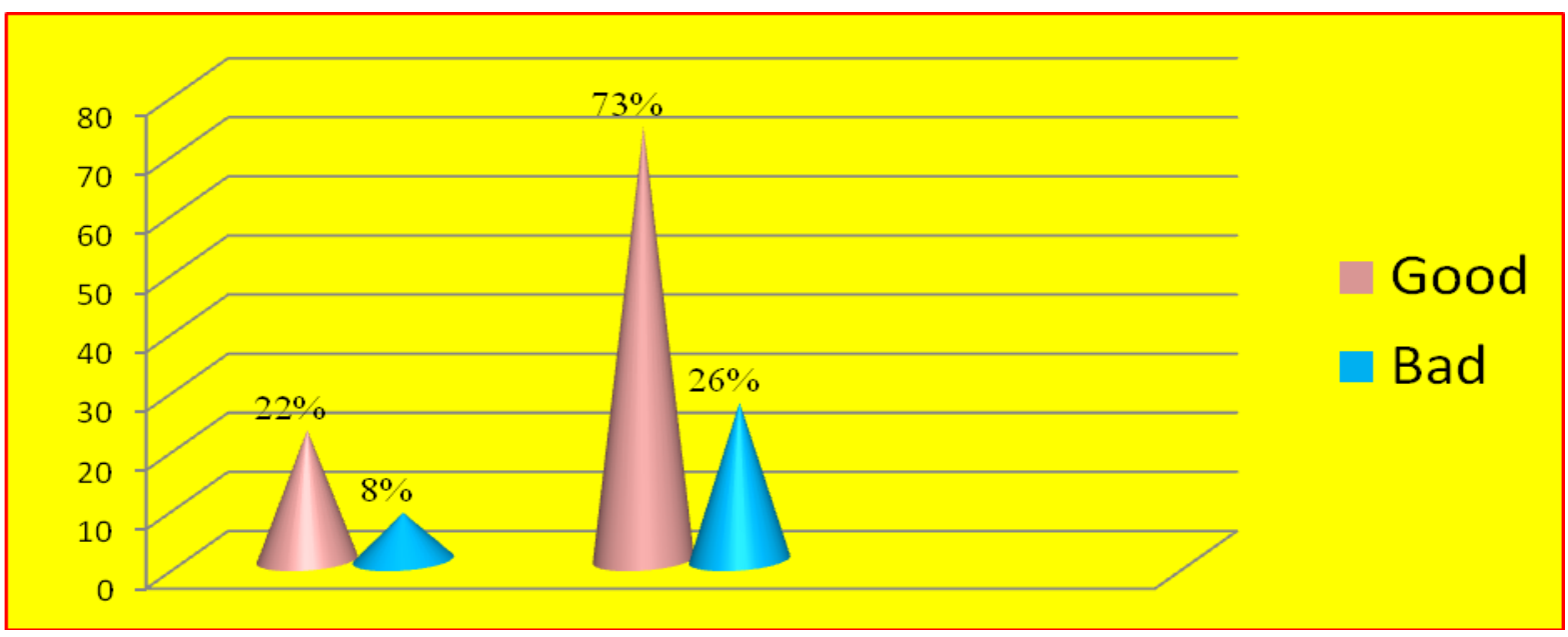

Most of the respondents (33\%) come under the age Range of 25-35 Years followed by 35-45 years $(26 \%)$ almost equal samples that is $(20 \%)$ comes under the age group below 25 years and more than 45 years.

Most of the respondents that is $(36 \%)$ come under BC category followed by SC (26\%), OC $(20 \%)$ and ST (16\%).

Most of the $33 \%$ of the respondents are illiterates followed by below $10^{\text {th }}$ class $23 \%$ an equal sample belongs to $10^{\text {th }}$ class and degree were as few $10 \%$ of the sample had studied intermediate. Majority of the 33 respondent of the sample monthly income 15,000-25000 followed by $30 \%$ where having income above 25,000 all most equal sample that 20\% and 16 $\%$ where having income between 10,000-15000 and less than 10,000 respectively.

Majority of the respondents $90 \%$ knows about the ICDS scheme were as more than half the respondents $60 \%$ didn't had information regarding SSY majority of the respondents that is $80 \%$ known about the KGBVs were as $77 \%$ did not had any information about the SABLA.

Majority of the respondents KGBVs girls (80\%) were as (50\%) girls in ICDS followed by (33\%) of lactating mothers and $16 \%$ of pregnant women. Benefitted were as $23 \%$ girls benefitted 
the SABLA Programme.

Most of the respondents $30 \%$ came to knew about these scheme through Grama panchayat meetings followed by advertisements on TV $23 \%$, SHG group $20 \%$ and newspapers $13 \%$ were as few of the respondents $7 \%$ knew through the family members and equal percentage that is $3 \%$ of the samples knew relatives and neighborhood.

Majority of the respondents (66\%) were not benefitted because of lack of awareness and no voter list and $(36 \%)$ of the respondents were not benefitted migration. And $30 \%$ of the respondents were not benefitted other reasons.

More than half the respondents Perceptions these programmes good for them were as $26 \%$ of the respondents had bad perception about these programmes.

\section{References}

Administrative Staff College of India 2013. "Evaluation of SABLA Scheme" A Report Submitted to Ministry of Women and Child Development. Government of India. Hyderabad, September. Available at http://wcd.nic.in/sites/default/files/1SablaEVAReportver5.1_0.pdf.

AICRP on Child Development L. L. PUJAR College of Rural Home Science S. C. HUNSHAL University of Agricultural Sciences, Dharwad, Karnataka K. B. BAILUR

Arati (2016) Arati Chakra and Dr. M Aruna. Influence of family variables on core affective life skills of youth.

Arora Samridhi, Bharti Shaveta and Mahajan Arti.2006.Evaluation of Non-Formal Pre
School Educational Services Provided at Anganwadi Centres (Urban Slums of Jammu City). Journal of Social Science. 12(2): 135-137.

Dhawan Sushma, S.P. Rahgir and Suman Agrawal 2002. Profile of rural women in ICDS programme. Madhya Journal of Extension Education, Vol. IV \& V, No.3, pp. 66-67.

Dr. M. Marimuthu and K. Indumathi Velmurugan. A Study with Special Reference to Banking Industry in India. International Journal of Management (IJM), 7(2), 2016, pp.

Mr. Rameshwar P. Rasal, Research Scholar in Economics, Shree Jagadish Prasad Jhabarnal Tiberwala University Rajasthan, India.' A Study of Sukanya Samriddhi Yojana in the post office of Thane District”. Rexjournal, ISSN 23211067, Renewable Research Journal. Volume 3 Issue 3.

Rawat, S. (2011). Status and functioning of Kasturba Gandhi Balika Vidyalaya Uttarkhand. VSRD Technical and NonTechnical Journal 2(II): 0976-7967.

V. Venkatachalam, Ph.D Research Scholar Department of Commerce; Dr. G. Ravindran, Assistant Professor, Department of Commerce, Tamilnadu. "Account Holder's Satisfaction Towards Sukanya Samriddhi Account of Postal Department With Special Reference To Coimbatore City." ISSN print-ISSN 0976-6421 and ISSN online-0976-643X. Volume 7, Issue 3, September December (2016).

www.google.co.in, are referred for the purpose of collecting the information/data.

www.sukanyasamriddhiacountyojana.in, www.sbi.co.in.

\section{How to cite this article:}

Prashanthi, B., R. Geetha Reddy and Spandana, B. 2019. To Study the Extent of Awareness and Utilization of the Selected Central Government Schemes by the Women. Int.J.Curr.Microbiol.App.Sci. 8(07): 2221-2228. doi: https://doi.org/10.20546/ijcmas.2019.807.270 